\title{
The Mobile Internet Contribution in Tourism
}

\author{
Daniela Garbin Praničević \\ University of Split, Faculty of Economics, Croatia \\ Anja Križan \\ 3T Software labs, Berlin, Germany \\ Judita Peterlin \\ University of Ljubljana, Faculty of Economics, Slovenia
}

\section{Abstract}

Daily use of mobile devices has become one of many living standards. The number of Internet users is increasing annually. Along with the mobile devices rising number, the need for responsive design also rises. The purpose of this research is threefold: firstly, to clarify, secondly, to explore, and thirdly, to discuss the role of mobile Internet in achieving tourism, particularly hotel strategic goals. The elaboration will be based on the mobile internet traffic history, in Croatia and globally. In the accordance with the above stated the authors collected the relevant data sample. Examples are: website visits, websites user conversions, share of realized reservations and transactions made on the websites via mobile devices to verify the significance of mobile Internet traffic for the tourism business. The research findings have the potential to contribute to the tourism manager's level of awareness regarding the role of mobile internet in tourism and hotel business. As additional contribution, it will be discussed the forthcoming perspectives of the mobile internet traffics and mobile internet future trend.

Key words: mobile Internet traffic, tourism, user experience JEL classification: M10, A22, O03, Z32

\section{Introduction}

Internet traffic refers to the traffic realized through mobile devices, such as: smart phones, tablet devices and other mobile devices with Internet access that is constantly growing proportionally with upward trend of internet searches. Nowadays, according to the Internet Live Stats (2018) around $40 \%$ of the world population has an internet connection, while the number of unique mobile internet users is about 3.7 billion (Statista, 2018). Over time, the way to access the Internet and Internet search is changing. Initially, there were just desktop devices (personal computers, desktops and laptops), but over time and due to Internet technology development, internet search has been realized more and more via mobile and tablet devices. Such shift deeply changes completely "informative" environment and ways of information flow (Castells et al. 2006).

According to the Google travel trends (2016), in the period 2014 - 2016, the majority of Internet searches realised by mobile usage was just focused on tourist service search. The named trends have shown how often users search for tourist services and related information through mobile devices. Consequently, even $70 \%$ of all mobile phone users said they were looking for tourist/guests information on their smartphones. Google travel trends (2016) also revealed that $85 \%$ travellers do not plan all activities before the trip, but only after, they arrive at the destination. Moreover, travel searches via mobile devices grow over $50 \%$, annually. 
Furthermore, the latter source discloses that the many mobile users use their mobile devices when they are already "on the road". The same principle can be applied to different tourism segments, such as booking accommodation, trips in destinations or restaurant seats. Statistics (Google travel trends, 2016) show that 31\% of leisure travellers and $53 \%$ business travellers have made their reservations by mobile. Almost half of the passengers who searched for information in that way approve that they made a purchase decision on their mobile phone, than changed the device and purchased the product. The mentioned indicated the following: (i) booking and purchasing processes on particular websites are still not sufficiently customized and responsive, and (ii) the mobile users feel lack of confidence or trust in particular websites and consequently avoid purchasing online (Gefen, 2002; Agag et al., 2016).

On the other side and despite the fact that increasing number of tourism related people recognize and actively use digital services over the internet (online booking through the web pages, social networking, etc.) still smaller number of them participate in mobile internet traffic and related opportunities.

Namely, Consumer Barometer Survey (2015) data provides more realistic perspective of the mobile device usage in Europe, referring recently booked hotel accommodation facilities (Figure 1). Accordingly, only $8 \%$ of hotel reservations were made by mobile devices, which refer to tablets and smart phones usage.

Figure 1

Devices Used to Make Hotel Reservations

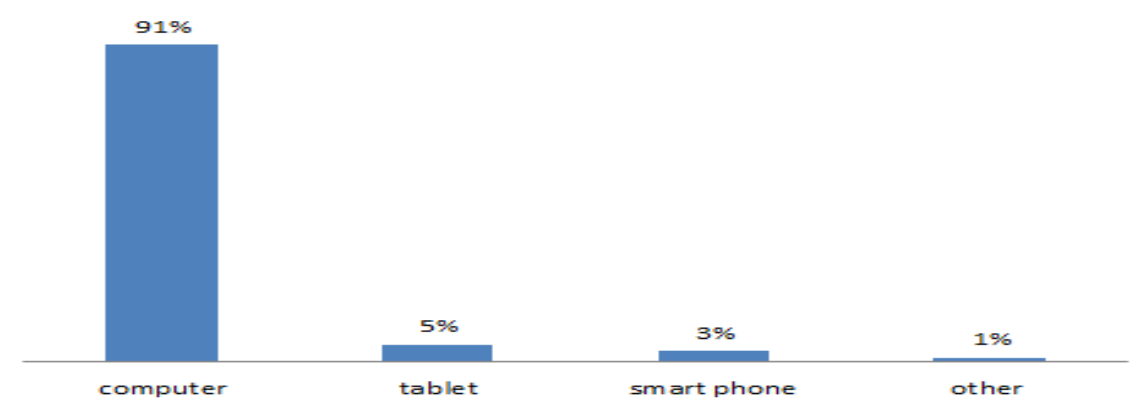

Source: Consumer Barometer Survey (2018)

The interesting fact is that mobile Internet searches for travel data exceed search rates on desktop devices over the weekend (Google, 2016). The named indicates that hotels and other tourism subjects websites have to provide responsive web design and accordingly make their web page to "look good", not only on desktops, but also on tablets, and smart phones. It means that hotels need to invest more effort and resources to increase their website responsiveness and thus better customize them to potential guests. Generally, if the hotel or any other company do not implement a suitable online mobile commerce strategy, the risk of losing the market, competitiveness and profit arises (The Integer Group, 2017). In other words, if hotels and other tourism companies miss to adapt to the online environment, they will inevitably lag behind their competitors. The relationship between Internet facilities and performances in tourism sector has been explored in studies (Sigala et al., 2004; Buhalis et al., 2007; Tsai et al., 2009; Law et al., 2010; Garbin Praničević et al., 2011). 


\section{Internet and mobile trends in Croatia}

According to the Consumer Barometer (2016), the number of internet users in Croatia also increases, annually. In $2013,70 \%$ of the population used the internet, in 2014 the percentage rose to 74\%, while the data for both, 2015 and 2016, showed a share of $73 \%$. Regarding the younger population (up to 35 years), the share of internet users is growing more significantly. Namely, in $2013,95 \%$ of such internet users were officially registered. The same data was $99 \%$ in 2016 . The number of smartphone users in Croatia was 65\% in 2016 compared with $39 \%$ three years ago. The share of younger users as defined above (up to 35) with own smartphone was $96 \%$ in 2016, while in 2013 the share was $70 \%$. On the other side, it is a fact that having smart phones really corresponds but not reveals the exact frequency of using them for on line search. The above-mentioned survey indicated that in the year $2016,65 \%$ of Croatian citizens used smartphones for the Internet search at least as much as they used computers for the same activity, while the same share in 2013 was $31 \%$. Within the younger population, this figure is 55\% for 2013 and $85 \%$ for 2016 (The Connected Consumer Survey, 2016).

According to the same source, $40 \%$ of users on their mobile device compare products and prices, $24 \%$ search for reviews and tips for the products and services they're interested in, $22 \%$ search for locations and directions, $16 \%$ of users search for where to buy a product/service online, $16 \%$ discovered a relevant brand /company for their research, and only $5 \%$ of users made contact with the seller via the mobile device (The Connected Consumer Survey, 2016).

\section{Empirical research}

The survey was conducted in the $1^{\text {st }}$ quarter of 2017 about 124 hotel and hotel chain websites in Croatia. Total of 124 named websites were distributed according to the following (Table 1):

Table 1

Web Sites Numbers by Category

\begin{tabular}{cc}
\hline Category/star & Objects / No \\
\hline 2 & 5 \\
3 & 68 \\
4 & 43 \\
5 & 3 \\
Hotel chain & 5 \\
\hline Source: Authors' work, N $=124$
\end{tabular}

The findings are provided within the three research parts.

First part of the research was focused on segments, such as website responsiveness, online booking capability, and online payment options. Regarding website responsiveness, in the research are explored the existence of a mobile site or responsive desktop version of hotel website. Regarding the category of online bookings, in this research is considered as follows: the website has the option of online booking if the current (automatic) booking confirmation is possible, without any additional, but separated confirmation. Regarding online payment category, the authors explored the presence of any form of payment online payment (mostly payment gateway system).

As far as all above-mentioned segments are considered, the findings are almost quite similar, and indicate that presence of responsive websites, online booking and 
online payment options on hotel websites depends upon the hotel category. In other words, websites of higher hotel category are better responsive, and have more developed both, online booking and online payment options, compared with websites of lower hotel category. The detailed related data are enclosed, as follows (Figure 2):

Figure 2

Website Responsiveness, Online Booking and Online Payment Options by Hotel Category

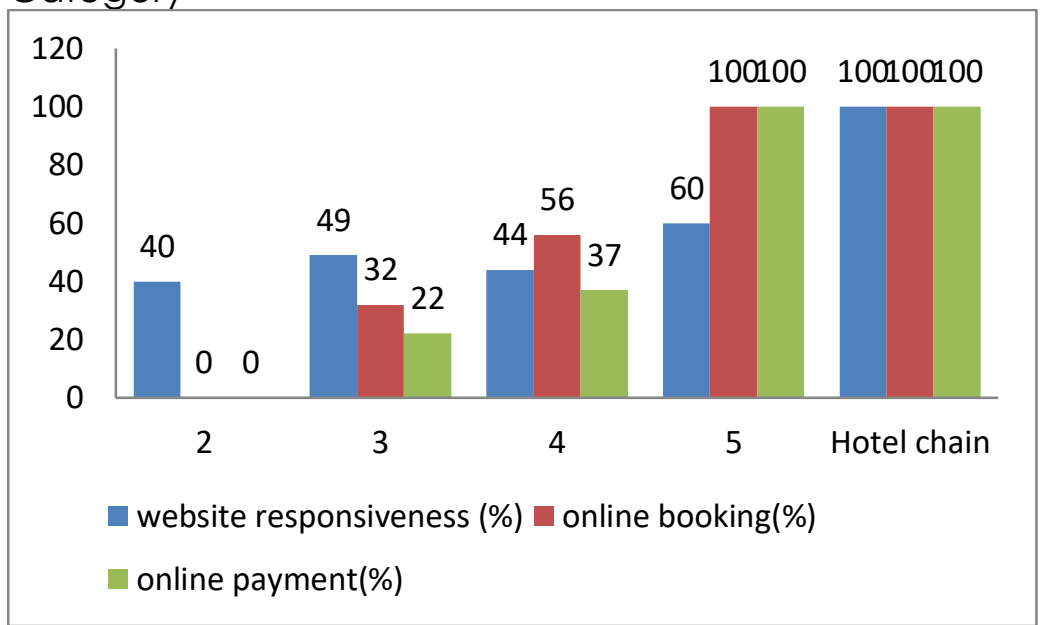

Source: Authors' work, $\mathrm{N}=124$

Second part of the research was focused on exploring the share of mobile traffic in total traffic. This part of research puts in focus the actual visit and the realized conversions through the tourist content website. As data source has been used the Google Analytics outputs. Such collected data were processed in the Microsoft Office Excel 2016.

Google Analytics tool provided web statistics on 7 hotel websites from $\mathrm{a} / \mathrm{m}$ sample observed from 2010 until 2017. The total is based on more than $35,000,000$ registered user visits. Due to the small sample, the collected data serve only as an indicator of the mobile internet traffic trend.

Devices were divided into 3 categories, such as desktop computers (personal computers), mobile devices, and tablet devices. Table 2 shows aggregated statistics referring on hotel websites visits realised in $\mathrm{a} / \mathrm{m}$ period. The research involved all customer visits, regardless of country or traffic sources.

Table 2

Hotels Web Site Visits by Devices

\begin{tabular}{cccc}
\hline Year & \multicolumn{3}{c}{ Web site visits - hotels } \\
\cline { 2 - 4 } 2010 & Desktop & Mobile & Tablet \\
2011 & $99 \%$ & $1 \%$ & $0 \%$ \\
2012 & $97 \%$ & $3 \%$ & $0 \%$ \\
2013 & $90 \%$ & $5 \%$ & $5 \%$ \\
2014 & $81 \%$ & $10 \%$ & $9 \%$ \\
2015 & $78 \%$ & $16 \%$ & $6 \%$ \\
2016 & $64 \%$ & $26 \%$ & $10 \%$ \\
2017 & $60 \%$ & $30 \%$ & $10 \%$ \\
\hline
\end{tabular}

Source: Authors' work, $\mathrm{N}=35.208 .541$ website visits 
The findings evident continuous decline in traffic realized by desktop and computers, and the growth in traffic realized by mobile and tablet devices. In 2013, growth was recorded on desktop computers and falls in traffic realized by mobile and tablet devices. Such inconsistency of the trend may be due to changes in the web site design either in the way of data tracking.

Third part of the research was focused on both, the role of mobile traffic regarding business results (reservations) and the share of mobile traffic in total traffic. Besides statistics used in previous section, in this part we used conversions (or eCommerce transactions) as new metric appropriate for hotel websites that have online booking and payment system. The results are as bellow (Table 3):

Table 3

E-Commerce Transaction Statistics

\begin{tabular}{cccc}
\hline \multirow{2}{*}{ Year } & \multicolumn{3}{c}{ E-commerce - hotels } \\
\cline { 2 - 4 } 2010 & Desktop & Mobile & Tablet \\
2011 & $100 \%$ & $0 \%$ & $0 \%$ \\
2012 & $99 \%$ & $1 \%$ & $0 \%$ \\
2013 & $94 \%$ & $1 \%$ & $5 \%$ \\
2014 & $90 \%$ & $6 \%$ & $4 \%$ \\
2015 & $96 \%$ & $2 \%$ & $2 \%$ \\
2016 & $86 \%$ & $5 \%$ & $9 \%$ \\
2017 & $79 \%$ & $6 \%$ & $15 \%$ \\
\hline
\end{tabular}

Source: Authors' work, $\mathrm{N}=35.208 .541$ website visits

Regarding E-commerce transactions realised by mobile device, it is evident less growth on mobile and tablet transaction than in previous research part focused on the web site visits realised by mobile devices. Many users still do not feel safe when it comes to online payments, especially through mobile devices, so when they pay online; they actually do it on desktop computers.

The chart below (Figure 3) indicates the growth in mobile Internet traffic regarding visits and conversions trend. The visit curve has a steep slope of conversion curves, which was expected due to fact that online booking and online payment options are not still supported by many websites. Despite the small sample of the data covered by this research, the trend of mobile Internet traffic growth is unquestionable.

Figure 3

Hotel Websites Visits and Conversions Realised by Mobile Devices/Growth Trend

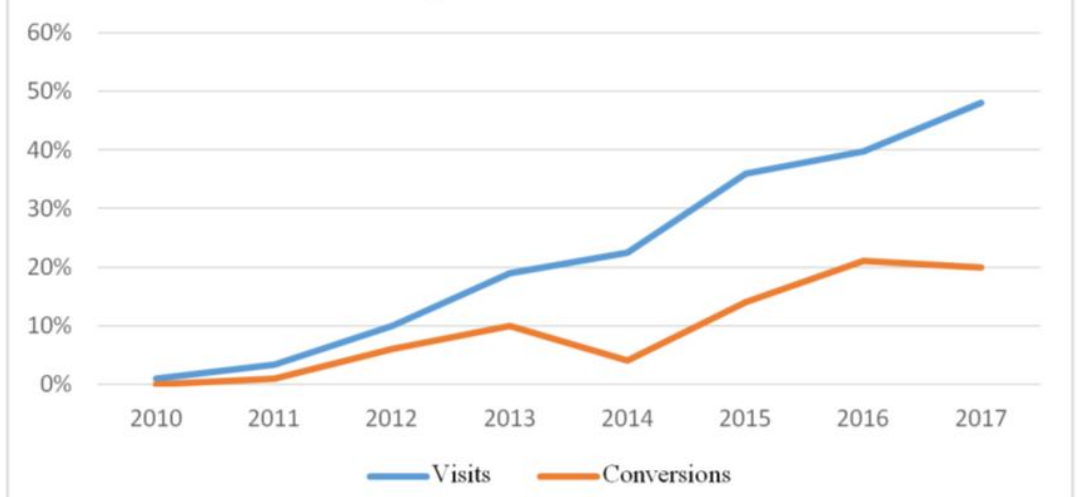

Source: Authors' work, $\mathrm{N}=35.208 .541$ website visits 


\section{Conclusions}

Mobile Internet traffic is growing annually. This trend closely corresponds with the significant growth in mobile devices (smartphones and tablets) sales and usage. Furthermore, the constant development of mobile device functionality will additionally facilitate the Internet searches through the mobile devices and thus support the Internet traffic trend.

The growth of internet traffic through mobile devices is present both, globally and locally, in Croatia. The population broadly use mobile devices in daily life. The tourism sector follows the same trend. The use of mobile devices is evident in all travel phases including both, informative and interactive activities. Namely, apart from the information search, there is registered an increase in online hotel goods and services purchase rate. The younger (up to 35) especially support stated trends since, following Burkhard et al. (2017) they prefer to be more independent regarding planning the entire trip (transportation, accommodation, activities, etc.). Moreover, in accordance with Google travel trends (2016) already two thirds of the younger travellers have no problem with running the entire process on their mobile devices. Finally, according CISCO Reports (2018) complemented with Gaugliemo (2018) considerations, the future rise in mobile traffic are expected to be continued primary due to a shift in device mix toward smarter devices, but also due to other factors such as: more mobile users, more mobile connections, more responsive design, more secure on line payments, etc.

\section{References}

1. Agag, G., El-Masry, A. (2016), „Understanding the determinants of hotel booking intentions and moderating role of habit", International Journal of Hospitality Management, Vol. 54, pp. 52-67.

2. Buhalis, D., Zoge, M. (2007), "The strategic impact of the internet on the tourism industry", In M. Sigala, L. Mich, Murphy, J. (Eds.), Information and Communication Technologies in Tourism, Springer-Verlag, Wien, pp. 481-492.

3. Burkhard, S., Kow, N., Fuggle, L. (2017), Travel Trend Report 2017, available at https://www.trekksoft.com/en/library/ebook-travel-trend-report-2017

(15 January 2018)

4. Castells, M., Fernandez-Ardevol, M., Qiu, J. (2006), Mobile Communication and Society, MIT Press, Cambridge.

5. CISCO Report (2018), available at https://www.cisco.com/c/en/us/solutions/serviceprovider/visual-networking-index-vni/index.html (20 February 2018)

6. Consumer Barometer Survey (2018), available at https://www.consumerbarometer.com/en/graphbuilder/?question=M1 \& filter=country :croatia (15 March 2018)

7. Garbin Praničević, D., Alfirević, N., Indihar Štemberger, M. (2011), "Information system maturity and the hospitality enterprise performance", Economic and Business Review, Vol. 13, No. 4, pp. 227-249.

8. Gaugliemo, C. (2018), "Mobile Traffic Will Continue To Rise, Rise, Rise as Smart Devices Take over the World", available at https://www.forbes.com/sites/connieguglielmo/2014/02/05/mobile-traffic-willcontinue-to-rise-rise-rise-as-smart-devices-take-over-the-world/\#7f1bf26a28a5 (20 March 2018)

9. Gefen, D. (2002.), „Reflections on the dimensions of trust and thrustworthiness among online consumers",ACM SIGMIS Database: the DATABASE for Advances in Information Systems, Vol. 33, No. 3, pp. 38-53.

10. Google (2016), Travel Trends 2016: Data Consumer Insights, available at https://www.thinkwithgoogle.com/advertising-channels/mobile/travel-trends-2016data-consumer-insights/ (15 February 2018) 
11. Internet Live Stats (2017), available at www.internetlivestats.com/internet-users/ (15 February 2018)

12. Law, R., Qi, S., Buhalis, D. (2010), „Progress in tourism management: A review of website evaluation in tourism research", Tourism Management, Vol. 31, No. 3, pp. $297-$ 313.

13. Sigala, M., Airey, D., Jones, P., Lockwood, A. (2004), "ICT paradox lost? A stepwise DEA methodology to evaluate technology investments in tourism settings", Journal of Travel Research, Vol. 43, No. 2, pp. 180-192.

14. Statista - the Statistics Portal (2018), available at https://www.statista.com/topics/1145/internet-usage-worldwide/ (01 March 2018)

15. The Connected Consumer Survey (2016), available at https://www.consumerbarometer.com/en/graphbuilder/?question=M1\&filter=country:croatia (01 February 2018)

16. The Integer Group (2017), The Checkout, The Integer Group.

17. Tsai, H., Song, H. Y., Wong, K. K. F. (2009), "Tourism and hotel competitiveness research", Journal of Travel \& Tourism Marketing, Vol. 26, No. 5-6, pp. 522-546.

\section{About the authors}

Daniela Garbin Praničević, PhD is an Associated Professor of business informatics at the Faculty of Economics, University of Split. In the named Faculty, she received her B.A. degree in Economics. Her M.A. degree is received in Information Management at the Faculty of Economics, University of Zagreb, and the Ph.D. degree in Business Informatics at the Faculty of Economics, University of Split. Her research interests are knowledge management, IT project management, and IT appliance in business, particularly in tourism and hospitality. She participated in few research projects and published papers based on the project results. Author can be contacted at daniela@efst.hr.

Anja Križan is a digital marketing specialist currently based in Berlin, Germany. She received her B.A. and M.A. degree in Information Management at the Faculty of Economics, University of Split. Her areas of interest are online marketing, user behaviour and web analytics. Author can be contacted at anja.krizan03@gmail.com.

Judita Peterlin, PhD is an Assistant Professor of management and organizational theory working as a research and teaching assistant at the Faculty of Economics, University of Ljubljana. She graduated from the Faculty of Social Sciences and Faculty of Economics University of Ljubljana. In the study year $2016 / 17$ she is a teaching assistant at the following courses: Foundations of management and organization, Management - English Track, Knowledge management, and Advanced management. Her main research interests are social innovation, leadership development, sustainability. Author can be contacted at judita.peterlin@ef.uni-lj.si. 